\title{
BIOLOGICAL ACTIVITY OF MACROMYCETES ISOLATED FROM CHILEAN SUBANTARCTIC ECOSYSTEMS
}

\author{
RODRIGO REINOSOI, DANIEL CAJAS-MADRIAGA', MIGUEL MARTÍNEZ ${ }^{2}$, AURELIO SAN MARTÍN \\ CLAUDIA PÉREZ', VÍCTOR FAJARDO AND JOSÉ BECERRA ${ }^{1 *}$
}

\author{
${ }^{1}$ Laboratorio de Química de Productos Naturales, Universidad de Concepción, Chile. \\ ${ }^{2}$ Laboratorio de Microbiología, Universidad de Concepción, Chile. \\ ${ }^{3}$ Departamento de Química, Universidad de Chile, Santiago, Chile. \\ ${ }^{4}$ Laboratorio de Productos Naturales, Universidad de Magallanes, Punta Arenas, Chile.
}

(Received: July 10, 2013 - Accepted: October 8, 2013)

\begin{abstract}
Twenty six compounds were identified by GC-MS analysis from culture broth of six Macromycetes growing in subantarctic forests in southern Chile: Mycena hialinotricha, Collybia butyracea, Inocybe geophylla, Entoloma nubigenum, Stropharia semiglobata and Psathyrella sp. Antifungal and antibacterial activity were evaluated through agar diffusion test. This assay showed bioactivity against Penicillium notatum, Fusarium oxysporum, Rhyzoctonia solani, Ceratocistys pilifera, Bacillus subtilis, Pseudomonas aeruginosa, Escherichia coli, Escherichia faecalis and Staphilococcus aureus.
\end{abstract}

Keywords: Fungi, subantarctic ecosystems, antibacterial, and antifungal activity, secondary metabolites.

\section{INTRODUCTION}

Microorganisms are recognized as prolific producers of bioactive natural products, many of them useful as clinical drugs ${ }^{1}$. In recent years, a large percentage of those have been isolated and identified from Basidiomycetes and the enormous potential of this group of organisms is now widely accepted in the scientific and industrial community ${ }^{2}$. Interesting compounds of different biogenetic origins have been isolated from mycelial fermentation with antibacterial, antifungal, cytostatic, antiviral, and other activity ${ }^{3,4,5}$.

Currently, efforts to discover new bioactive compounds have been focused on fungi inhabiting Chilean subantarctic ecosystems, considering that this territory is not enough studied in terms of biological and chemical diversity of Macromycetes. In fact, the land stretching from $42^{\circ} \mathrm{S}$ to the southernmost end of the continent is the least studied in terms of biodiversity of fungi. Therefore, it is important to extend the study of our mycological heritage and evaluate their potential biological activity ${ }^{6}$.

This study has investigated the bioactive extracts and its chemical constituents obtained from fermentation of six strains of saprophytes fungi: Mycena hialinotricha, Collybia butyracea, Inocybe geophylla, Entoloma nubigenum, Stropharia semiglobata, and Psathyrella sp. (Agaricales, Basidimycota), isolated from forests near to Concepción and Punta Arenas. It's reported the presence of nitrogenous compounds, 3-(2-methylpropyl)2,3,6,7,8,8a-hexahydropyrrolo[1,2-a]pyrazine-1,4-dione, 1 H-Indole-3 methyl, 1H-indole-3-carboxylic acid methyl ester, 3-benzyl-6-isopropyl-piperazine2,5-dione, 1H-indole-6-methyl, phenolic compounds, and terpenes, like $\beta$-selinene, and Valencene related to the activity of these compounds against to pathogenic bacteria and fungi.

\section{EXPERIMENTAL}

The samples of Collybia butyracea (TUDEC050), Mycena hialinotricha (TUDEC212), Entoloma nubigenum (TUDEC105), Inocybe geophylla (TUDEC101), and Psathyrella sp. (TUDEC030) were obtained from forests near to Concepción (36 49'52"S - 72 54' $40^{\circ}$ ”W), VIII Región, and sample of Stropharia semiglobata (RM047) was obtained at Punta Arenas (56 06' $20^{\circ}$ 'S $-71^{\circ} 01^{\prime}$ 50' W), XII Región, Chile. All mycelia were isolated from spore prints of fruiting bodies of fungi, which were then grown in a YMG medium (yeast extract $4 \mathrm{~g}$, malt extract $10 \mathrm{~g}$, glucose $4 \mathrm{~g}$ and $20 \mathrm{~g}_{\text {agar L }} \mathrm{L}^{-1}$ distilled water) augmented with $200 \mathrm{mg} \mathrm{L}{ }^{-1}$ of streptomycin sulphate ${ }^{7}$. Cultures were incubated to $22^{\circ} \mathrm{C}$. The strains were deposited at the cepario de la Universidad de Concepción and were maintained at $4^{\circ} \mathrm{C}$, subculturing every 12 months.

Small sections of the each stock culture were transferred to a $5 \mathrm{~L}$ Erlenmeyer flask containing $3 \mathrm{~L}$ of YMG medium (pH 5.8). This flask was incubated at $22^{\circ} \mathrm{C}$ on a rotary shaker $(120 \mathrm{rpm})$. After 20 days of fermentation, the mixture was filtered and culture broth was extracted exhaustively with
EtOAc $(500 \mathrm{~mL})^{8}$. The organic phase was dried on anhydrous $\mathrm{Na}_{2} \mathrm{SO}_{4}$, filtered, and concentrated with a rotary evaporator $\left(120 \mathrm{rpm}, 40^{\circ} \mathrm{C}\right)^{9}$, yielding a crude extract (S. semiglobata $(973 \mathrm{mg})$, Psathyrella sp. (408 mg), I. geophylla (891 $\mathrm{mg})$, C. butyracea $(550 \mathrm{mg})$, M. hialinotricha $(993 \mathrm{mg})$, E. nubigenum (350 $\mathrm{mg})^{10}$.

There extracts were analyzed by GC-MS on a Hewlett Packard gas chromatograph 5890A, coupled to Hewlett Packard 5975 mass spectrometer system equipped with a $30 \mathrm{~m}$ long, $0.25 \mathrm{~mm}$ id, $0.25 \mu \mathrm{m}$ film thickness HP5MS capillary column. The temperature was programmed from $100^{\circ} \mathrm{C}$ to $275^{\circ}$

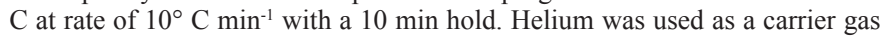
with a constant flow at $1.4 \mathrm{~mL} \mathrm{~min}{ }^{-1}$. The ionization voltage was $70 \mathrm{eV}$. The compounds identification was performed by comparison the obtained spectra with those reported in the literature and mass spectra with authentic samples. When such samples were not available tentative structures were proposed on the basis of the mass spectral fragmentation with comparison spectral library NIST 2005 (NIST /EPA/NIH MASS 2005 spectral Library) ${ }^{11}$. A volume of $1 \mu \mathrm{L}$ of the sample at the concentration of $10 \mathrm{mg} / \mathrm{mL}$ was injected. Spectra were considered coincident if the similarity index was higher than $95 \%$. In addition, the spectra were compared with Kovats retention index. The chemical characterization of obtained extracts was performed with these compounds.

Antibacterial activity of the crude extracts was qualitatively evaluated by diffusion test in agar. Plates with Mueller-Hinton agar were inoculated with a concentration $10^{8} \mathrm{CFU} / \mathrm{mL}$ of Bacillus subtilis, Pseudomonas aeruginosa, Escherichia coli, Escherichia faecalis, and Staphilococcus aureus. Paper disks Whatmann $\mathrm{N}^{\circ} 1(6 \mathrm{~mm})$ were impregnated with $100 \mu \mathrm{g} / \mathrm{disc}$ of the fraction obtained. The kanamycin antibiotic was used as control. Cultures were incubated at $37^{\circ} \mathrm{C}$ by $24 \mathrm{~h}^{12}$.

The phytopathogens Penicillium notatum, Fusarium oxysporum, Rhyzoctonia solani, Pythium debaryanum, and Ceratocistys pilifera were used as target species for the antifungal assay. Plates with YMG agar were inoculated with a concentration $10^{6}$ spores $/ \mathrm{mL}$ of these microorganisms. Paper disks Whatmann $\mathrm{N}^{\circ} 1(6 \mathrm{~mm})$ were impregnated with $100 \mu \mathrm{g} / \mathrm{disc}$ of the fraction obtained, benomyl was used as control. Petri dishes were incubated at $22^{\circ} \mathrm{C}$ by 21 days ${ }^{13}$. Antifungal activity as well as antibacterial activity was determined by displaying an inhibitory halo around disk. All assays were performed in triplicate.

\section{RESULTS AND DISCUSSION}

Six culture broth extracts from Chilean Macromycetes isolated from subantarctic forests were assessed for antibacterial and antifungal activities. The extracts exhibited considerable activity, demonstrating the existence of interesting bioactive compounds (see Table 1). Antibacterial assay showed activity against Bacillus subtilis, Pseudomonas aeruginosa, Escherichia coli, Escherichia faecalis and Staphilococcus aureus. Extracts of Psathyrella sp., 
I. geophylla, M. hialinotricha and E. nubigenum exhibits higher antibacterial activities towards B. subtilis, however, extracts of $S$. semiglobata and C. butyracea showed a moderate activity. S. aureus showed a moderate susceptibility to the antibacterial activity of the extracts of $S$. semiglobata,
I. geophylla, C. butyracea, M. Hialinotricha, and E. nubigenum. Whereas, I. geophylla and $S$. semiglobata extracts exhibits low and diffuse antibacterial effect against $E$. coli and P. aeruginosa. E. faecalis was susceptible to the obtained extracts of Psathyrella sp. and E. nubigenum.

Table 1. Antimicrobial activity of Chilean macromycetes in agar diffusion test.

\begin{tabular}{|c|c|c|c|c|c|c|c|c|}
\hline & \multicolumn{7}{|c|}{ Diameter of inhibition zone (mm)* } \\
\hline & TUDEC030 & TUDEC050 & TUDEC101 & TUDEC105 & TUDEC212 & RM047 & kanamycin & benomyl \\
\hline Bacillus subtilis & 19 & 8 & 14 & 17 & 15 & 8 & 14 & $\mathrm{x}$ \\
\hline Pseudomonas aeruginosa & - & $7 \mathrm{di}$ & $7 \mathrm{di}$ & - & - & $7 \mathrm{di}$ & - & $\mathrm{x}$ \\
\hline Escherichia coli & - & - & 7 & - & - & 9 & 12 & $\mathrm{x}$ \\
\hline Escherichia faecalis & 16 & - & - & 9 & - & 9 & 10 & $\mathrm{x}$ \\
\hline Staphilococcus aureus & - & 7 & 7 & 9 & 8 & 8 & 11 & $\mathrm{x}$ \\
\hline Penicillium notatum & 9 & - & 12 & 11 & 17 & 7 & $\mathrm{x}$ & 15 \\
\hline Fusarium oxysporum & 9 & - & 6 & - & - & - & $\mathrm{x}$ & 19 \\
\hline Rhyzoctonia solani & 8 & 8 & 6 & - & 9 & 7 & $\mathrm{x}$ & 17 \\
\hline Pythium debaryanum & - & - & - & - & - & - & $\mathrm{x}$ & 15 \\
\hline Ceratocistys pilifera & 15 & 13 & - & 7 & 13 & 8 & $\mathrm{x}$ & 18 \\
\hline
\end{tabular}

* diameter disk $=6 \mathrm{~mm}$, concentration $=100 \mu \mathrm{g} / \mathrm{disc} ;-=$ No inhibition zone; $\mathrm{di}=$ diffuse inhibition zone; $\mathrm{x}=$ No tested.

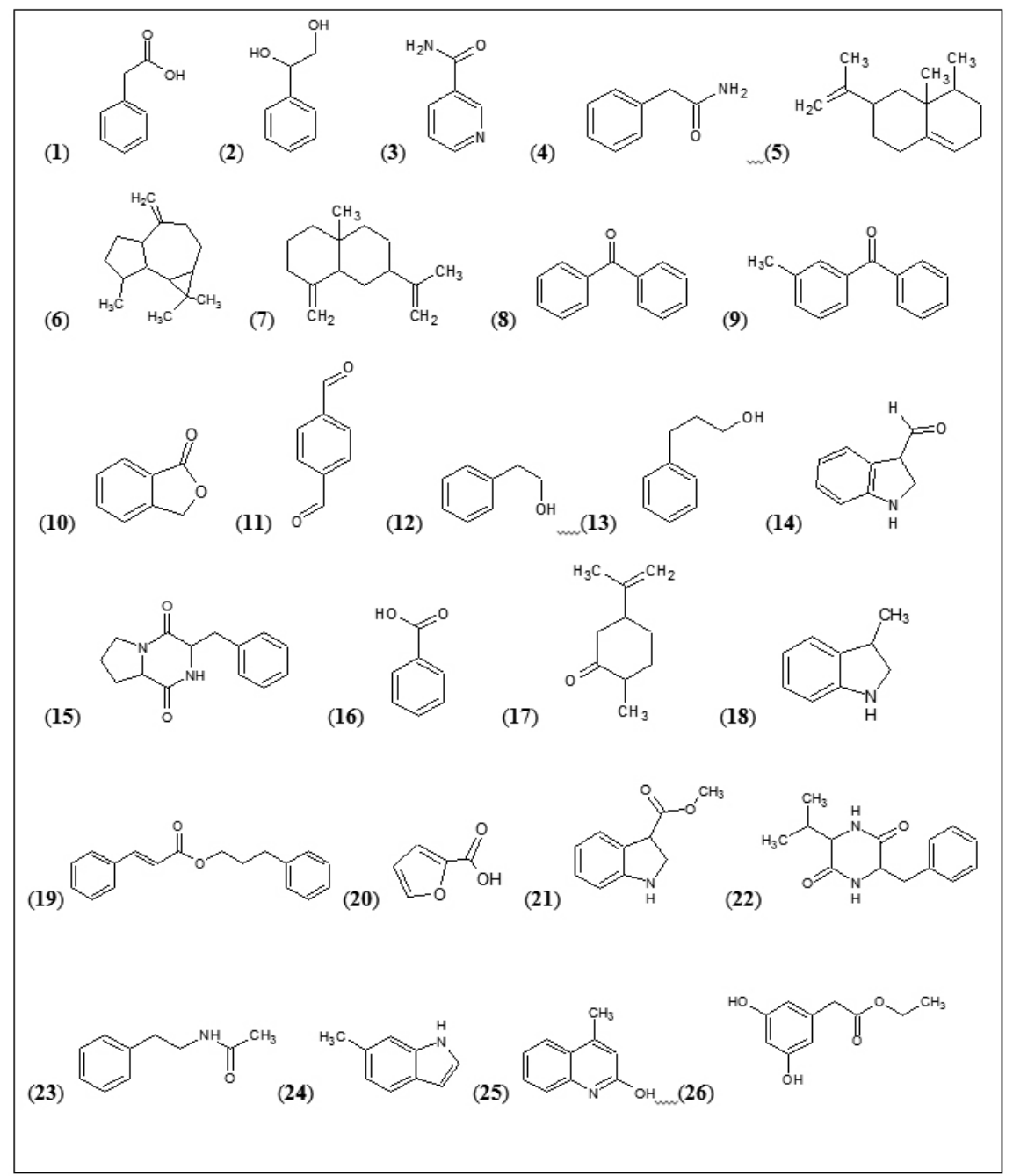

Fig. 1. Compounds structures obtained by comparison spectral library NIST 2005. 
J. Chil. Chem. Soc., 58, № 4 (2013)

Table 2. GC-MS data of the compounds in extracts from liquid cultures.

\begin{tabular}{|c|c|c|c|}
\hline Compounds & $\mathrm{M}^{+}$and characteristic ions $(\%)$ & $\begin{array}{c}\mathrm{RT} \\
(\min . \mathrm{s})\end{array}$ & $\begin{array}{l}\text { Estimated } \\
\text { Kovats RI }\end{array}$ \\
\hline \multicolumn{4}{|l|}{ Psathyrella sp. } \\
\hline Phenylacetic acid (1) & 136(30), 118(5), 92(20), 91(100), 65(20), 51(7) & 8.20 & 1262 \\
\hline (1S)-1-Phenyl-1,2-ethanediol (2) & 138(8), 107(100), 79(73), 77(48), 51(77) & 9.21 & 1298 \\
\hline pyridine-3-carboxamide (3) & 122(100), 106(64), 78(87), 51(50) & 10.30 & 1426 \\
\hline 2-phenylacetamide (4) & 135(17), 92(84), 91(100), 65(31), 51(12) & 10.45 & 1302 \\
\hline Valencene (5) & 204(20), 189(18), 162(100), 107(54), 93(34), 81(33), 51(27) & 13.36 & 1491 \\
\hline \multicolumn{4}{|l|}{ Collybia butyracea } \\
\hline Aromadendrene (6) & $\begin{array}{c}204(18), 161(30), 147(25), 133(30), 119(32), 150(50), 91(100), 79(60), \\
67(40), 55(35)\end{array}$ & 11.17 & 1474 \\
\hline$\beta$-selinene (7) & $\begin{array}{c}\text { 204(60), 189(50), 161(55), 147(25), 133(55), 121(65), 105(100), 98(10), } \\
81(95), 67(70), 55(63)\end{array}$ & 12.61 & 1530 \\
\hline Diphenylmethanone (8) & 182(55), 152(5), 126(3), 105(100), 77(60), 51(26) & 13.30 & 1603 \\
\hline (3-methylphenyl)-phenylmethanone (9) & 196(60), 181(9), 165(3), 119(100), 105(27), 91(30), 77(21), 51(10) & 14.50 & 1716 \\
\hline 3H-2-benzofuran-1-one (10) & 134(100), 105(90), 77(58), 63(7), 51(23), 50(20) & 15.37 & 1207 \\
\hline p-benzenedicarboxaldehyde (11) & 134(100), 133(89), 105(60), 77(50), 51(92) & 16.71 & 1284 \\
\hline \multicolumn{4}{|l|}{ Inocybe geophylla } \\
\hline 2-phenylethanol (12) & 122(23), 103(5), 91(100), 77(56), 65(23), 51(9) & 5.59 & 1121 \\
\hline 3-phenyl-1-propanol (13) & 136(20), 117(80), 91(100), 79(16), 77(25), 65(25) & 7.83 & 1219 \\
\hline 1H-Indole-3-carboxaldehyde (14) & 145(100), 144(67), 117(20), 116(65), 90(13), 63(12), 62(6) & 14.99 & 1476 \\
\hline $\begin{array}{l}\text { 3-(phenylmethyl)-2,3,6,7,8,8a- } \\
\text { hexahydropyrrolo[1,2-a]pirazine-1,4-dione (15) }\end{array}$ & 244(45), 200(9), 153(37), 125(100), 120(12), 91(50) & 19.60 & 2138 \\
\hline \multicolumn{4}{|l|}{ Entoloma nubigenum } \\
\hline Benzoic acid (16) & 105(100), 122(83), 94(15), 77(66), 51(33) & 6.68 & 1180 \\
\hline 2-methyl-5-(prop-1-en-2-yl)-cyclohexanone (17) & $152(12), 138(6), 122(100), 106(60), 78(90), 55(80), 51(75)$ & 10.40 & 1600 \\
\hline 3-methyl-1H-indole (18) & 131(100), 103(10), 95(40), 77(20), 51(10) & 10.74 & 1264 \\
\hline 3-phenylprop-2-enyl 3-phenylprop-2-enoate (19) & 266(45), 262(5), 131(100), 117(20), 101(30), 81(20), 65(35), 55(30) & 21.85 & 1583 \\
\hline \multicolumn{4}{|l|}{ Mycena hialinotricha } \\
\hline Furan-2-carboxylic acid (20) & 112(100), 95(59), 83(4), 66(7) & 4.30 & 999 \\
\hline 2-phenylethanol (12) & 122(23), 103(5), 91(100), 77(56), 65(23), 51(9) & 5.60 & 1136 \\
\hline 3-phenyl-1-propanol (13) & 136(21), 117(88), 91(100), 79(16), 77(26), 65(25) & 7.90 & 1235 \\
\hline Phenylacetic acid (1) & 136(30), 118(5), 92(20), 91(100), 65(20), 51(7) & 8.17 & 1262 \\
\hline 1H-indole-3-carboxylic acid methyl ester (21) & 175(53), 167(7), 144(100), 116(18), 89(16), 63(7) & 17.57 & 1531 \\
\hline 3-benzyl-6-isopropyl-piperazine-2,5-dione (22) & 246(45), 208(20), 127(50), 91(100), 70(60), 55(90) & 18.66 & 1976 \\
\hline $\begin{array}{c}\text { 3-(phenylmethyl)-2,3,6,7,8,8a- } \\
\text { hexahydropyrrolo[1,2-a]pyrazine-1,4-dione (15) }\end{array}$ & 244(45), 200(9), 153(37), 125(100), 120(12), 91(50) & 19.60 & 2138 \\
\hline \multicolumn{4}{|l|}{ Stropharia semiglobata } \\
\hline N-(2-phenylethyl)acetamide (23) & 163(12), 104(80), 103(5), 91(15), 72(10), 65(4) & 9.20 & 1492 \\
\hline 1H-Indole-6 methyl (24) & 131(100), 130(90), 115(5), 103(6), 91(6), 65(15), 77(10) & 9.63 & 1288 \\
\hline 3-methyl-2(1H)-Quinolinone (25) & 159((75), 131(25), 130(100), 103(10), 77(13), 51(10) & 11.01 & 1401 \\
\hline Ethyl(3,5-dihydroxyphenyl)acetate (26) & 196(51), 124(37), 123(100), 69(85), 67(10), 57(10), 55(11) & 16.21 & 1700 \\
\hline
\end{tabular}


The agar diffusion test showed that the extract of native fungi were active against phytopathogenic fungi Penicillium notatum, Fusarium oxysporum, Rhyzoctonia solani, and Ceratocistys pilifera producing inhibition halos of different intensities (see Table 1). F. oxysporum showed a diffuse susceptibility to the antifungal activity of the extracts of Psathyrella sp. and I. geophylla. S. semiglobata showed moderate activity against $P$. notatum, $R$. solani and $C$. pilifera. The obtained extracts from liquid cultures of M. hialinotricha exhibit higher antifungal activities towards $P$. notatum, $R$. solani and $C$. pilifera. It is interesting to note that the extract produced by M. hialinotricha strain TUDEC212 was active against pathogenic fungi, this effect could be result of presence the active substances, probably ecologically significant in nature, where this specie produces antifungal compounds that gives competitive advantages against potential competitors 8 .

Psathyrella sp. showed low effect towards P. notatum, $F$. oxysporum, $R$. solani and $C$. pilifera. Finally, it was observed that $E$. nubigenum extract showed antifungal activity against $P$. notatum and $C$. pilifera; these fungi causing the "blue stain" of wood and actually their control is not possible.

The findings of our results showed that the extracts of I. geophylla (TUDEC101) and Psathyrella sp. (TUDEC030) had significant antifungal activity against a $F$. oxysporum pathogenic strain; this fungus is causing lesions at basal level of the stem similar to cortical cankers and disease known as damping-off ${ }^{14}$. This pathogen causes considerable economic losses in agroforestry industry, for this reason, our results suggest the use of compounds biosynthesized by Inocybe and Psathyrella as natural products for their control.

When the extracts were subjected to GC-MS analysis to find out the components produced by the fungus, it was observed peaks in agree to fungal bioactive compounds. Interpretation of mass spectrum GC-MS was conducted using the database of National Institute Standard and Technique (NIST). The spectrum of the component was compared with the data stored in the NIST library. The name, molecular weight, ionic fragmentation patterns, structure of the compounds was ascertained (see Figure 1, Table 2).

Six compounds were identified in extract of Collybia butyracea (TUDEC050) by GC-MS analysis. This extract containing $\beta$-selinene (7), diphenylmethanone (8), (3-methylphenyl)-phenylmethanone (9), 3H-2benzofuran-1-one (10), p-benzenedicarboxaldehyde (11) showed activity against $S$. aureus, $B$. subtilis, $P$. aeruginosa, $C$. pilifera and $R$. solani. $\beta$-selinene (7) was isolated from Plectranthus amboinicus and antitumor, antibacterial, anti inflammatory and fungicide activities were reported ${ }^{15}$.

Seven compounds were identified in liquid culture extract of Mycena hialinotricha (TUDEC212), furan-2-carboxylic acid (20), 2-phenylethanol (12), 3-phenyl-1-propanol (13), phenylacetic acid (1), 1H-indole-3-carboxylic acid methyl ester (21), 3-benzyl-6-isopropyl-piperazine-2,5-dione (22), 3-(phenylmethyl)-2,3,6,7,8,8a-hexahydropyrrolo[1,2-a]pirazine-1,4-dione (15). The bioactivity of these compounds is consistent with previous studies. Mycena species uses the shikimic acid pathway thereby antifungal compounds strobilurins ${ }^{8}$; the compounds identified by GC-MS analysis have similar structure to fungicide strobilurin A isolated from Strobilurus tenacellus, Oudesmansiella mucida, and Mycena sp. ${ }^{16}$, suggesting that were synthesized by the same pathway.

In extract of Stropharia semiglobata (RM47) were determined 4 compounds: acetamida, $\mathrm{N}-(2$-phenylethyl) acetamide (23), $1 \mathrm{H}$-Indole-6 methyl (24), 3-methyl-2(1H)-quinolinone (25), and ethyl (3,5-dihydroxyphenyl)acetate (26). Four compounds were detected in Inocybe geophylla (TUDEC101), 2-phenylethanol (12), 3-phenyl-1-propanol (13), 1H-Indole-3-carboxaldehyde (14) and 3-(phenylmethyl)-2,3,6,7,8,8a-hexahydropyrrolo[1,2-a]pirazine-1,4dione (15). These molecules were isolated previously from fungi Aporpium caryae $^{17}$, Agrocybe cylindracea ${ }^{18}$, and Lactarius subplinthogalus ${ }^{19}$, antifungal and bactericidal activities were reported.
Chromatographic analysis determined 5 compounds in Psathyrella sp. (TUDEC030), Phenylacetic acid (1), (1S)-1-Phenyl-1,2-ethanediol (2), pyridine-3-carboxamide (3), 2-phenylacetamide (4) and Valencene (5). Whereas, in extract of Entoloma nubigenum (TUDEC105) were detected four compounds, benzoic acid (16), 2-methyl-5-(prop-1-en-2-yl)-cyclohexanone (17), 3-methyl-1H-indole (18) and 3-phenylprop-2-enyl 3-phenylprop-2enoate (19), and antimicrobial was reported in this studies (see Table 1).

\section{CONCLUSIONS}

The obtained results in antimicrobial assays crude extracts of macromycetes isolated from subantarctic forests indicate their potential generation of bioactive metabolites. These fungi are therefore good sources for exploring the possibility of new antimicrobial drugs discovery. It is suggested the need to further investigation the potential application of the bioactive secondary metabolites in agroforestry industry as control of phytopathogenic agents.

\section{ACKNOWLEDGEMENTS}

Authors would like to thank the financial support from the Project Fondecyt No 1110656, Universidad de Concepción and CONICYT for its Doctoral Scholarship Program.

\section{REFERENCES}

1. A. Gunatilaka. J. Nat. Prod. 69, 509, (2006)

2. K. Lorenzen, T. Anke. Cur. Org. Chem. 2, 329, (1998)

3. F. Eilbert, M. Engler-Lohr, H. Anke, O. Sterner. J. Nat. Prod. 63, 1286 , (2000)

4. E. Thines, F. Eilbert, H. Anke, O. Sterner. Biotechnology. 2, 328, (2000)

5. B. Köpcke, M. Johansson, O. Sterner, H. Anke. J. Antibiotics. 55, 40, (2002)

6. P. Aqueveque, J. Becerra, G. Palfner, M. Silva, J. Alarcón, T. Anke, O. Sterner. J. Chil. Chem. Soc. 51, 1059, (2006)

7. M. Madigan, J. Martinko, D. Stahl, D. Clark. Brock Biology of Microorganisms. (13 Eth) Pearson Education, San Francisco, USA. 2012

8. P. Aqueveque, T. Anke, H. Anke, O. Sterner, J. Becerra, M. Silva. $J$ Antibiot. 58, 61, (2005)

9. P. Davoli, R. Weber. Mycologist. 16, 102, (2002)

10. A. San-Martín, S. Orejarena, C. Gallardo, M. Silva, J. Becerra, R. Reinoso, M. Chamy, K. Vergara, J. Rovirosa. J. Chil. Chem. Soc. 53, 1388, (2008)

11. N. Tram, M. Mitova, V. Bankova, N. Handjieva, S. Popov. Z. Naturforsch. 57, 239, (2002)

12. W. Bailey, G. Scott. Diagnóstico Microbiológico. Editorial Panamericana. Buenos Aires. 2004

13. H. Anke, O. Bergendorff, O. Sterner. Food. Che. Toxic. 27, 393, (1989)

14. F. Lops, F. Cibelli, M. Raimondo. Plant Disease. 97, 846, (2013)

15. M. Uma, S. Jothinayaki, S. Kumaravel, P. Kalaiselvi. New York Sci. J. 2011; 4, 66, (2011)

16. G. Von Jagow, G. Gribble, B. Trumpower. Biochemistry. 25, 775, (1986)

17. L. Levy, G. Cabrera, J. Wright, A. Seldes. Phytochemistry. 54, 941, (2000)

18. K. Won-Gon, L. In-Koung, K. Jong- Pyung, R. In-Ja, K. Hiroyuki, Y. IckDong. J. Nat. Prod. 60, 721, (1997)

19. Y. Wang, S. Yang, Y. Wu, J. Yue. Nat. Prod. Research. 18, 159, (2004) 